\title{
Real Time Control of Combined Sewer Overflows: the SWIFT Model
}

\author{
Alain Mailhot, Andrée Bilodeau, Claude Blanchette, \\ Christiane Marcoux, Pierre Lavallée and Jean-Pierre Villeneuve
}

Combined sewer overflows (CSOs) have been recognized as one of the major causes of poor receiving water quality in urban areas. Among the many solutions proposed to solve this problem, real time control (RTC) is one of the most promising. The objective of RTC is to minimize CSO by optimizing water volumes stored in sewer systems during rain events. This is done by using control devices (regulators) and storage tanks. Control can be local or global. An operational RTC model, the SWIFT model, has been developed and tested on the Communauté Urbaine de Québec (C.U.Q) sewer network. SWIFT is a model that uses a global strategy to define optimal regulator operations in order to minimize total overflow volume. It has been calibrated and applied to the C.U.Q network. In order to compare the efficiency of RTC using SWIFT with static control, simulations using 56 rain events from 1988 were performed on the West part of the C.U.Q network. Significant reductions of the CSO frequency and of the overflow volumes were obtained.

\subsection{Introduction}

In recent years, it has been demonstrated that CSOs during rain events have a significant impact on the water quality of receiving environments (Field and Turkeltaub 1981; Lavallée et al. 1984). Several solutions have been proposed to

Mailhot, A., A. Bilodeau, C. Blanchette, C. Marcoux, P. Lavallee and J. Villeneuve. 1999. "Real Time Control of Combined Sewer Overflows: the SWIFT Model." Journal of Water Management Modeling R204-15. doi: 10.14796/JWMM.R204-15.

(C) CHI 1999 www.chijournal.org ISSN: 2292-6062 (Formerly in New Applications in Modeling Urban Water Systems. ISBN: 0-9697422-9-0) 
reduce and control these overflows (Patry et al. 1982; Stahre 1986). Many authors consider that RTC of combined sewers is an efficient technology to reduce the impact of overflows on the receiving streams (Trotta et al. 1977; Nguyen et al. 1982; Patry et al. 1982; Delattre et al. 1986; Wilson 1988). Overflows are minimized by optimizing water volumes stored in the system; this is achieved by efficiently controlling the regulators of the sewer system.

Several control strategies are available to achieve real time management of combined sewers, but the most frequently used are the local reactive control (LRC) and global predictive control (GPC) (Wilson et al. 1988). In a LRC, the regulation devices are operated independently from each other, at each time step, to respond to the current system conditions. The LRC minimizes the total overflow volume by providing an optimal use of the storage capacity.

A GPC considers the global sewer control facilities in planning regulation actions. Therefore, applying a GPC requires that the coming state of the system be predicted over a sufficiently long period to allow flow propagation from one control device to the next. Thus, the model must simulate urban surface runoff as well as the flow in the sewer pipes, on the basis of rainfall intensity predictions (e.g. by a radar prediction method). Contrary to the LRC, the GPC optimizes the volumes stored in the system by taking into account the combined effects of actions taken at the head of the system on structures located downstream. And by considering directly the quality of the wastewater circulating in the system, it is also possible to have more specific environmental objectives, such as reducing the total concentration of contaminants released, or to minimize the impacts of the discharge on the environment (Patry and Marino 1982; Nguyen Van and Osseyrane 1987; Wilson 1988).

The real time implementation of a GPC implies that an optimal action plan must be assessed and defined in a time frame shorter than the smallest time step considered. For example, if a five minute time step is considered, the operations should be optimized after three minutes to allow for the modification of the structure configuration in the following two minutes. This time constraint represents one of the main limitations of real time control implementation (TenBroek and Brink 1996).

Recognizing the significant environmental impacts of the overflows of its combined sewers, the Communauté Urbaine de Québec implemented a real time control system based on the GPC approach. Indeed, studies conducted on the C.U.Q. territory indicated that the frequency of its overflows and the quality of the wastewater discharged have significant negative impacts on the receiving environments. In Québec City for example, overflows occur more than once every five days, between May 15 and September 15 (Lavallée and Lessard 1984). These overflows contribute to a general degradation of the receiving environments, which may last 2 to 3 days after an event (Lavallée et al. 1984). 
Implementing global predictive control on the C.U.Q. territory was made possible by developing a simulation-optimization model: the SWIFT model. The main objective of the C.U.Q. in using real time control is to restore maximal water uses by the population. To reach this objective, the SWIFT model optimizes the storage capacity of existing structures (intercepting sewers, tunnels) during rain events. The optimal use of intercepting sewers limits the size requirements of residual overflow detention reservoirs.

In the context of the C.U.Q. sewer network, the SWIFT model satisfies the calculation time constraints associated with RTC. The model simulates the main processes at work (surface runoff, conduit flow); a comparison of simulation results obtained with the SWIFT model with the results provided by the SWMM model, calibrated on the same network, shows that they are similar.

The first section of this chapter (see Section 15.2) introduces the general structure of the SWIFT model. The second section describes the application of the SWIFT model to the C.U.Q. sewer network management with a description of the structure and main features of the C.U.Q. network. Finally, the results of a comparison study between GPC and static control are presented in section 15.4. This study simulates all the rain events occurring on the C.U.Q. territory during the summer of 1988 .

\subsection{The SWIFT Model}

\subsubsection{Network Representation by SWIFT}

The network is represented by three elements: the secondary, primary and major axis (see. Figure 15.1). The secondary axis includes the drainage basins and the sewer pipes located immediately below these basins. These sewer pipes are therefore grouped in a secondary axis in order to simplify and accelerate modeling of the basins-conduits network. As a result, the model does not simulate the flows in either of the individual sewer pipes, but only the flow at a secondary axis outlet. Downstream from the secondary axis are the primary and major axis, comprising a series of conduits and network regulators. Regulators with fixed opening (uncontrolled) must all be located on primary axis, while the major axis includes all the controlled regulators. Usually, a primary axis links a secondary axis to the major axis.

\subsubsection{General Presentation of the SWIFT Model}

The SWIFT model has four modules: (i) a secondary axis model, (ii) a hydraulic model, (iii) an objective function, and (iv) an optimization algorithm. These modules have the respective functions to simulate urban surface runoff in the network drainage basins, to simulate water flow in the sewer pipes, and to minimize overflow volumes in accordance with a series of system operation 


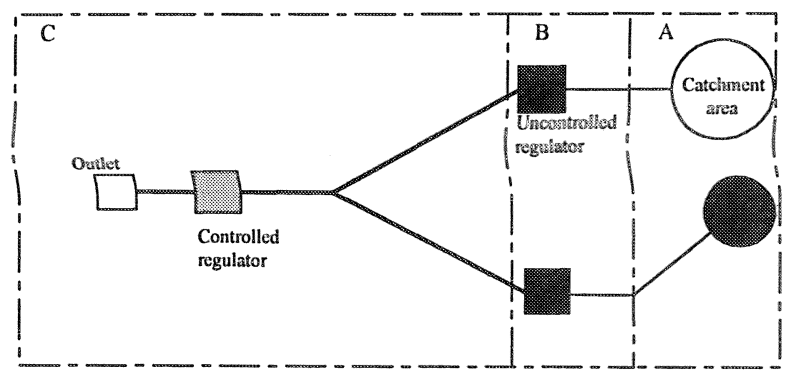

Figure 15.1 Example of network representation by SWIFT. (A) Secondary axis, (B) primary axis, and (C) major axis.

constraints. To operate properly, the inputs required by the model to simulate urban surface runoff will be provided by a radar prediction system, which measures and predicts rainfall intensity from radar imagery through a pattern recognition method. Precipitation intensity prediction is conducted over a fixed time interval known as the prediction period. Figure 15.2 presents the SWIFT model simulation-optimization algorithm. Sections 15.2 .2 to 15.2 .4 describe the different modules of the SWIFT model.

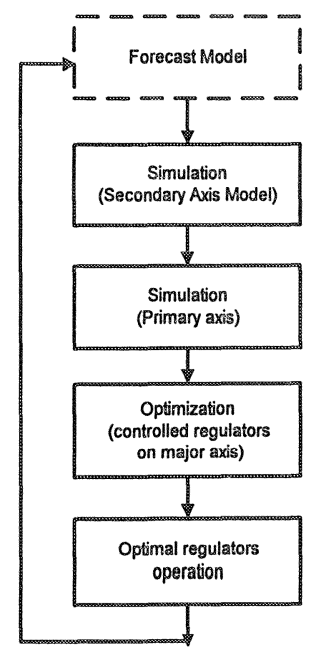

Figure 15.2 SWIFT model's algorithm.

\subsubsection{Secondary Axis Model}

The objective of the secondary axis model is to evaluate the hydrograph at the outlet of each secondary axis using their respective hyetograph. This model has four modules to simulate: (i) surface runoff, (ii) flow in sewer pipes, 
(iii) evaporation, and (iv) dry-weather flow. First, the model simulates runoff on pervious and impervious surfaces by transforming a water height into a runoff rate. Next, the dry-weather flow (sewer and infiltration flows) is added to the runoff rate. Then the model calculates the flow at the secondary axis outlet by simulating the effects of in-pipe flow (time lag and smoothing of initial hydrograph). Finally, when rainfall ends, the model simulates water evaporation at the surface of the basin.

\subsubsection{Sewer Pipe Flows Hydraulic Models Applied to Primary and Major Axis}

Two hydraulic models are used to simulate water flow in the network pipes located in the primary and major axis. The first one is adapted from the Muskingum-Cunge model (Ponce and Yevjevich 1978), which simulates open channel flows, and the second is a linear model (piston model) for surcharged flows. Contrary to the secondary axis model which reproduces the global effect of pipe flows, the Muskingum model and the piston model simulate water flow from pipe to pipe.

The proposed model will not simulate the transition between an open channel flow and a surcharged flow, or vice-versa. However, using the piston flow model, it simulates flows in surcharged pipes. This model supposes no damping and the output hydrograph is obtained by simply lagging the input hydrograph.

\subsubsection{The Objective Function of the SWIFT Model}

The selection of optimal controlled regulator openings proceeds through a series of system operation constraints. These constraints are addressed by the objective function which is as follows:

$$
\begin{aligned}
& f=\sum_{j=1}^{n b_{r g g}} \sum_{t=1}^{n b_{\text {bht }}} w_{j} \max \left[\left(Q_{a}{ }^{(j)}(t)-Q_{r}{ }^{(j)}\right) 0\right] \\
& +w_{s} \sum_{j=1}^{n b} \sum_{t=1}^{c o n} \max \left[\left(Q_{j}(t)-Q_{\max }^{(j)}\right), 0\right] \\
& +w_{v} \sum_{j=1}^{n b} \sum_{t=2}^{r e g} \sum_{t=2}^{n b} d t\left|Q_{r}^{(j)}(t)-Q_{r}^{(j)}(t-\Delta t)\right|
\end{aligned}
$$


where:

$$
\begin{aligned}
\mathrm{nb}_{\mathrm{dt}}= & \text { number of simulation steps forming the prediction } \\
& \text { period; } \\
n b_{\text {reg }}= & \text { number of controlled regulators in the network; } \\
\mathrm{nb}_{\mathrm{con}}= & \text { number of pipes forming the major axis; } \\
\mathrm{w}_{\mathrm{j}}= & \text { penalty factor associated with regulator } \mathrm{j} \text {, giving a } \\
& \text { different relative weight to overflows at different con- } \\
& \text { trolled regulators; } \\
\mathrm{Q}_{\mathrm{a}}{ }^{(j)}(\mathrm{t})= & \text { flow rate in the pipe above regulator } \mathrm{j} \text { at time } \mathrm{t} ; \\
\mathrm{Q}_{\mathrm{r}}(\mathrm{j})(\mathrm{t})= & \text { maximum allowable flow at regulator } \mathrm{j} \text { at time } \mathrm{t} ; \\
\mathrm{w}_{\mathrm{s}}= & \text { penalty factor for overloading of pipes; } \\
\mathrm{Q}_{\mathrm{j}}(\mathrm{t})= & \text { flow calculated downstream of pipe } \mathrm{j} \text { at time } t ; \\
\mathrm{Q}_{\max }= & \text { maximum allowable flow in pipe } \mathrm{j} \text {; and, } \\
\mathrm{w}_{\mathrm{v}}= & \text { penalty factor on the variation of regulator openings. }
\end{aligned}
$$

The first term of the objective function, proportional to the overflow volume, minimizes the total overflow volume for all the regulators and for the complete duration of the prediction period. The second term is proportional to the importance of overloading of the major axis; it equals zero when there is no overloading. The final term admits a small variation between regulator openings from one time interval to the next. The relative importance of specific overflows, overloading and control actions at regulators is taken into account by weighing each term of the objective function by parameters $w_{\mathrm{j}}, \mathrm{w}_{\mathrm{r}}$ and $\mathrm{w}_{\mathrm{s}}$. The values retained for these parameters result in solutions with overloading being less favored, since they are not compatible with the models used. Parameters $w_{j}$ associated with the regulators allow the impacts of discharges at each regulator allow to be balanced and stabilized.

\subsubsection{Optimization Algorithm}

The optimization algorithm used to minimize the objective function is the Powell algorithm (Powell 1965; Press et al. 1988). Once the flows upstream of the controlled regulators have been calculated for all the time intervals forming the prediction period, the Powell algorithm initializes the opening of the controlled regulators and evaluates the flow in the pipes located downstream from these regulators for the duration of the prediction period (see Figure 15.2). Finally, the model estimates the value of the objective function and iterations are repeated with new values for operation of the regulators until the minimum value of the function has been reached. 


\subsection{Application of the SWIFT Model to the C.U.Q. Network}

\subsubsection{Presentation of the C.U.Q. Network}

The C.U.Q. territory includes 13 municipalities covering an approximate surface area of $550 \mathrm{~km}^{2}$ (see Figure 15.3). The C.U.Q. is divided into the West catchment and the East catchment. These are serviced by an interception network which directs wastewater towards two distinct treatment plants (see Figure 15.3). Treated wastewater is then released into the St. Lawrence River by diffusers.

About $25 \%$ of the C.U.Q. territory is densely urbanized, mainly near surface waters. It is also on this part of the territory that we find combined sewers. The C.U.Q sewer network has a total of 70 regulators and 30 of them will eventually be controlled. As shown above, the C.U.Q. network is relatively complex and large. Therefore, it constitutes a very interesting example of real time control implementation (Lavallée et al. 1995).

\subsection{Comparison Between GPC and Static Manage- ment Methods}

A performance analysis was conducted to assess the results gained from using a GPC approach rather than a static approach. The static control mode is the current network management strategy of the C.U.Q., in which the capacity of regulation devices is established at the maximum dry-weather flow value. The experiment was conducted in the western portion of the C.U.Q territory (see Figure 15.3).

Comparison between the two control modes was conducted on all 56 rain events which occurred on the C.U.Q. territory during the summer of 1988, a representative average summer (Villeneuve et al. 1992). From these 56 rainfalls, the C.U.Q. West network was simulated in static mode and in dynamic mode using the SWIFT model.

A total of six overflow points are controlled in the West catchment, hereby identified as sites A, B, C, D, E and F. Comparative results are presented only for sites $\mathrm{A}, \mathrm{B}, \mathrm{C}$ and $\mathrm{D}$, since site $\mathrm{F}$ never overflows in GPC mode while overflows at site $\mathrm{E}$ are totally stored in a tunnel in the intercepting sewer. Table 15.2 gives the total overflow volumes obtained for both control modes examined, and the overflow volumes obtained at each site for the GPC mode alone. Also, it is known that in the static control mode, regulators are set for the maximum dry-weather flow which is exceeded for any precipitation greater than $2 \mathrm{~mm}$. An overflow indicates a volume released of at least $100 \mathrm{~m}^{3}$. 


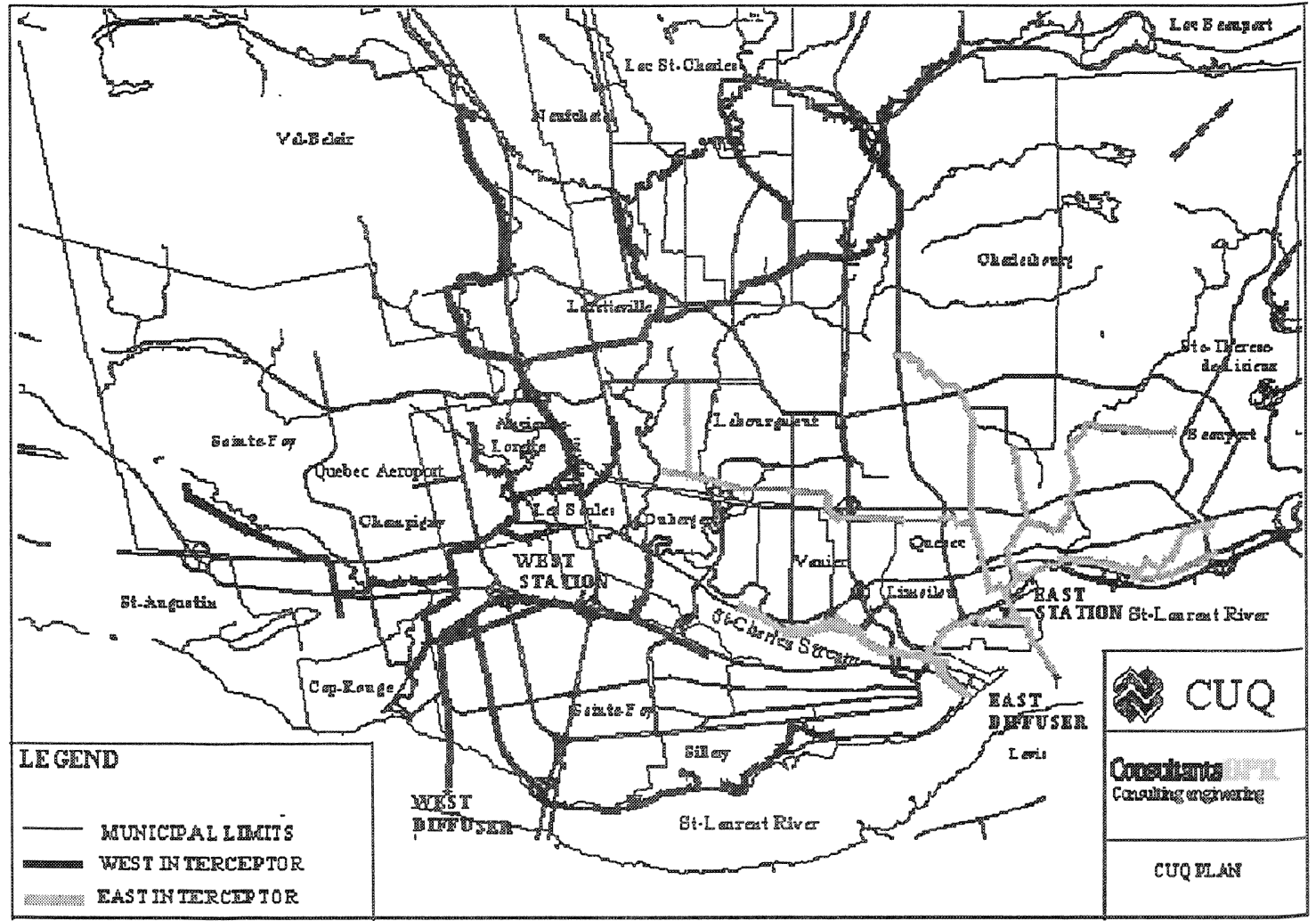

Figure 15.3 Overall plan of the C.U.Q. 
Table 15.2 Total overflow volumes with GPC vs static control (summer 1988 rain events).

\begin{tabular}{|c|c|c|c|c|c|c|c|}
\hline \multicolumn{6}{|c|}{ GPC } & \multirow[b]{2}{*}{ Static } & \multirow[b]{2}{*}{$\begin{array}{c}\% \text { of } \\
\text { Overflow } \\
\text { reduction }\end{array}$} \\
\hline Rain & Site A & Site B & Site C & Site D & Total GPC & & \\
\hline $10-07.88$ & 5592 & 10275 & 21467 & 16715 & 54049 & 93770 & $42 \%$ \\
\hline $4-08-88$ & 3768 & 7873 & 15239 & 13342 & 40222 & 62250 & $35 \%$ \\
\hline $28-08-88$ & 2019 & 4964 & 10554 & 8250 & 25787 & 43900 & $41 \%$ \\
\hline $14 b-08-88$ & 3766 & 6989 & 12549 & 11435 & 34739 & 55902 & $38 \%$ \\
\hline $6.08-88$ & 1231 & 2894 & 6282 & 5352 & 15759 & 35936 & $56 \%$ \\
\hline $11-07-88$ & 2525 & 4867 & 11735 & 8074 & 27201 & 38712 & $30 \%$ \\
\hline $26-07-88$ & 1170 & 2537 & 6399 & 4827 & 14933 & 27079 & $45 \%$ \\
\hline $15-08-88$ & 986 & 1992 & 3723 & 3231 & 9932 & 27808 & $64 \%$ \\
\hline $24-08-88$ & 25 & 668 & 1779 & 1971 & 4418 & 20639 & $79 \%$ \\
\hline $14 b-07-88$ & 777 & 1778 & 2777 & 2964 & 8296 & 21664 & $62 \%$ \\
\hline $26-08-88$ & 80 & 1247 & 3963 & 3681 & 8891 & 21982 & $60 \%$ \\
\hline $22-06-88$ & 1081 & 2150 & 5083 & 4066 & 12380 & 24710 & $50 \%$ \\
\hline $28-06-88$ & 603 & 1361 & 4879 & 3585 & 10428 & 34003 & $69 \%$ \\
\hline $16-05-88$ & 154 & 1304 & 3221 & 2587 & 7266 & 30245 & $76 \%$ \\
\hline $13-08-88$ & 118 & 957 & 3136 & 2460 & 6671 & 16658 & $60 \%$ \\
\hline $23-05-88$ & 63 & 732 & 1727 & 1521 & 3980 & 11825 & $66 \%$ \\
\hline $4 b-09-88$ & 0 & 25 & 680 & 685 & 1365 & 23543 & $94 \%$ \\
\hline $30 b-07-88$ & 0 & 158 & 1036 & 1087 & 2281 & 9377 & $76 \%$ \\
\hline $5-06-88$ & 0 & 16 & 474 & 579 & 1053 & 11186 & $91 \%$ \\
\hline $1 b-07-88$ & 0 & 327 & 1006 & 899 & 2232 & 13998 & $84 \%$ \\
\hline $25-06-88$ & 6 & 5 & 356 & 430 & 786 & 13140 & $94 \%$ \\
\hline $13-09-88$ & 0 & 0 & 0 & 0 & 0 & 9472 & $100 \%$ \\
\hline $30 a-06-88$ & 0 & 0 & 0 & 129 & 129 & 4305 & $97 \%$ \\
\hline $10-08-88$ & 0 & 0 & 0 & 101 & 101 & 2679 & $96 \%$ \\
\hline $23-06-88$ & 0 & 0 & 0 & 0 & 0 & 3299 & $100 \%$ \\
\hline $3 a-08-88$ & 0 & 0 & 0 & 0 & 0 & 3440 & $100 \%$ \\
\hline $12-0-88$ & 0 & 0 & 0 & 0 & 0 & 3806 & $100 \%$ \\
\hline $26-05-88$ & 0 & 0 & 0 & 0 & 0 & 9354 & $100 \%$ \\
\hline $20 a-06-88$ & 0 & 0 & 0 & 0 & 0 & 2909 & $100 \%$ \\
\hline $28 \mathrm{c}-06-88$ & 0 & 0 & 0 & 0 & 0 & 2696 & $100 \%$ \\
\hline $9-07-88$ & 0 & 0 & 0 & 0 & 0 & 5014 & $100 \%$ \\
\hline $30 b-06-88$ & 0 & 0 & 0 & 0 & 0 & 3381 & $100 \%$ \\
\hline $28 a-06-88$ & 0 & 0 & 0 & 0 & 0 & 3248 & $100 \%$ \\
\hline $12-07-88$ & 0 & 0 & 0 & 0 & 0 & 3880 & $100 \%$ \\
\hline $3 b-08-88$ & 0 & 0 & 0 & 0 & 0 & 2135 & $100 \%$ \\
\hline $9-08-88$ & 0 & 0 & 0 & 0 & 0 & 2310 & $100 \%$ \\
\hline $14 a-08-88$ & 0 & 0 & 0 & 0 & 0 & 6095 & $100 \%$ \\
\hline $6-09-88$ & 0 & 0 & 0 & 0 & 0 & 2045 & $100 \%$ \\
\hline $14 a-07-88$ & 0 & 0 & 0 & 0 & 0 & 2041 & $100 \%$ \\
\hline $14-09-88$ & 0 & 0 & 0 & 0 & 0 & 2872 & $100 \%$ \\
\hline $22-07-88$ & 0 & 0 & 0 & 0 & 0 & 1317 & $100 \%$ \\
\hline $19 b-07-88$ & 0 & 0 & 0 & 0 & 0 & 1944 & $100 \%$ \\
\hline $19 a-07-88$ & 0 & 0 & 0 & 0 & 0 & 2146 & $100 \%$ \\
\hline $1 a-07-88$ & 0 & 0 & 0 & 0 & 0 & 0 & $\underline{-\infty}$ \\
\hline $21-05-88$ & 0 & 0 & 0 & 0 & 0 & 1530 & $100 \%$ \\
\hline $2-06-88$ & 0 & 0 & 0 & 0 & 0 & 616 & $100 \%$ \\
\hline $4 a-09-88$ & 0 & 0 & 0 & 0 & 0 & 1145 & $100 \%$ \\
\hline $26-06-88$ & 0 & 0 & 0 & 0 & 0 & 356 & $100 \%$ \\
\hline $19 \mathrm{c}-07-88$ & 0 & 0 & 0 & 0 & 0 & 282 & $100 \%$ \\
\hline $20 b-06-88$ & 0 & 0 & 0 & 0 & 0 & 0 & $\longrightarrow$ \\
\hline $16-07-88$ & 0 & 0 & 0 & 0 & 0 & 0 & - \\
\hline $30 a-07-88$ & 0 & 0 & 0 & 0 & 0 & 0 & - \\
\hline $28 b-05-88$ & 0 & 0 & 0 & 0 & 0 & 0 & - \\
\hline 8-08-88 & 0 & 0 & 0 & 0 & 0 & 0 & - \\
\hline $21-07-88$ & 0 & 0 & 0 & 0 & 0 & 0 & - \\
\hline $5-08-88$ & 0 & 0 & 0 & 0 & 0 & 0 & - \\
\hline & & & & TOTAL & 292889 & 722644 & $60 \%$ \\
\hline
\end{tabular}


The results shown in Table 15.2 indicate that the number of overflows is reduced by $50 \%$ in the West catchment when a GPC is used rather than a static control. In static management situations, 48 overflows were recorded while only 23 overflows were observed in the GPC mode during the summer of 1988 . Depending on the site examined, the overflow reduction frequency varied between $54 \%$ and $73 \%$. Thus, site A overflows only 13 times, site B 18 times, site C 21 times and site D 22 times. Finally, according to the results presented in Table 15.4 , the overflow volume reduction varies from one rain event to another by $30 \%$ to $100 \%$, when using the GPC management approach rather than the static control approach. Over the course of the summer of 1988 , the overflow volume reduction is of the order of $60 \%$, the total overflow volume decreasing from $722644 \mathrm{~m}^{3}$ in the static mode to $292899 \mathrm{~m}^{3}$ in the GPC mode.

\subsection{Conclusion}

Combined sewer overflows (CSOs) are a major source of contamination of urban streams. The volume of these overflows must be reduced to assure better stream water quality. The SWIFT model allows real time control of combined sewer overflows by using a GPC approach. The main objective of the SWIFT model is to minimize the volumes of wastewater released by optimizing wastewater volumes stored in the network, while respecting the calculation time constraint associated with real time control. It also distributes the overflow volumes by considering the sensitivity of the environment at the various discharge points. The SWIFT simulation results are similar to those obtained with the SWMM model, calibrated using observations from the same network. The model is currently being implemented and will begin operating soon on the C.U.Q. network.

The GPC approach used by SWIFT has undeniable advantages compared to the static control currently used to manage the C.U.Q. network. Indeed, the results of a performance study of the model indicate a wastewater overflow volume reduction ranging from $30 \%$ to $100 \%$ depending on the rain event, and an overflow frequency reduction ranging from $54 \%$ to $73 \%$ depending on the concerned site. Using the SWIFT model to manage the C.U.Q. network optimizes the operation of existing control devices. In the context of the ultimate goal of maximum restoration of water uses by the population on the C.U.Q. territory, the GPC approach helps design cheaper residual overflow retention reservoirs.

On-going work should increase the performance of the SWIFT model. These studies address the following aspects: (i) modeling of overloads, (ii) taking into account uncertainties in rain predictions to avoid risks of overloading and flow inversion (Bilodeau et al. 1997), (iii) and using real time flow measurements available for certain points of the network to compensate for rain prediction uncertainties. 


\section{References}

Bilodeau, A. 1997. Impact des erreurs de prédiction de la pluie sur le contrôle en temps réel des réseaux d'égouts unitaires. (To be pulished in the Canadian Journal of Civil Engineering).

Delattre, J.M., Bachoc, A., and Jacquet, G.1986. Performance of Hardware Components for Real Time Management of Sewer Systems. Urban Runoff Pollution, Nato ASI Series, Springer-Verlag, 819-842.

Field, R, and Turkeltaub, R. 1981. Urban Runoff Receiving Water Impacts: Program Overview. Journal of the Environmental Engineering Division, ASCE, 107(EE1), 83100.

Huber, W.C., Heaney, J.P., Nix, S.J., Dickinson, R.E. and Polman, D.J. 1984. Storm Water Management Model User's Manuel - Version 3. U.S. Environmental Protection Agency, Cincinnati, Ohio, USA.

Lavallée, P., Marcoux, M., Villeneuve, J.P, Blanchette, C., and Dumont, Y. 1995. Le potentiel de la gestion automatisée pour le contrôle des déversements en temps de pluie. Americana 1995, Montréal, presentation without proceedings.

Lavallée, P. and Lessard, P. 1984. Importance de la contamination des débordements de réseaux unitaires. Sciences et techniques de l'eau, 17(4) : 353-357.

Lavallée, P., Lessard, P., and Villeneuve, J.P. 1984. Water Quality Variations in Running Waters due to Combined Sewer Overflowing. Evaluation of Negative Infuence. Proc., 3rd Int. Urban Storm Drainage Conf., Göteborg, Sweden, June 4-8, Göteborg : Chalmers University of Technology, 761-769.

Nguyen Van, H.N., and Osseyrane, M. 1987. Contrôle centralisé des régulateurs de l'intercepteur nord de la Communauté Urbaine de Montréal. Sciences et techniques de l'eau, 20 (1), 37-52.

Nguyen Van, H.N., Osseyrane, M., and Mc Pherson, M.B. 1982. Integrated Control of Combined Sewer Regulators. Journal of the Environmental Engineering Division," ASCE, 108 (EE6), 1342-1360.

Patry, G., Marchi, G., and Rousselle, J. 1982. Prédiction des débits de ruissellement pour le contrôle des réseaux d'égouts unitaires. Revue canadienne de génie civil, 9, 537. 548.

Patry, G.G., and Marino, M.A. 1982. Real-Time Control of Combined Sewer Systems : Short-Term RunoffForecast Models. Urban Drainage System: Proceeding of the first International Seminar, Refeatherstone and James (Eds), pp. 4135-4148. Southampton, September 1982. Boston: Computational Mechanical Center.

Ponce, V.M., and Yevjevich, V. 1978. Muskingum-Cunge method with variable parameters. Proceedings of the ASCE, 104 (HY12), 1663-1667.

Powell, M.J.D. 1965. A Method for Minimizing a Sum of Squares of Non-Linear Functions Without Calculations Derivates. The Computer Journal, 7, 303-307.

Press, W.H., Flannery, B.P., Teukolsky, S.A. and Vetterling, W.T. (1988). Numerical Recipes in $\mathrm{C}$, the Art of Scientific Computing. Cambridge University Press.

Stahre, P. 1986. Structural Measures for Runoff Quality Management. Urban Runoff Pollution, NATO ASI Series,Springer-Verlag, 701-712.

TenBroek, M.J. and Brink, P.N. 1996. Comparison of Available Continuous Modeling Techniques Using Benchmarking. Proceeding of Urban Wet Weather Pollution: 
Controlling Sewer Overflows and Stormwater Runoff Specialty Conference, Water Environment Federation (Ed.), pp 2-37 - 2-48, Québec City, June 1996.

Trotta, P.D., Labadie, J.W., and Grigg, N.S. 1977. Automatic Control Stategies for Urban Stormwater. Journal of the Hydraulic Division, 103 (HYR), 1443-1459.

Ward, A.D. and Eliot, W.J. 1995. Environmental Hydrology. CRC Press Inc., Lewis Publishers, Boca Raton, Florida, 462 p.

Wilson, L. 1988. "Le contrôle en temps réel des réseaux d'égouts unitaires." Ph. D. Thesis, Québec, INRS-Eau, Université du Québec.

Wilson, L., Isabel, D., and Villeneuve, J.P. 1988. Contrôle en temps réel de l'impact des débordements de réseaux unitaires. Sciences et techniques de l'eau, 21 (2), 141-145. 